affected by the introduction of the earth system, no evidence has come to my knowledge. To judge by our home experience, however, this (or whatever may be its Indinn analogue) is the 'fever' which mas most be reduced in prevalence by the substitution of good for bad conservancy arrangements.

"After all, in India as in England, it is probably not from gross death returns that trustworthy evidence as to the relation between each particular fever and the current system of conservancy arrangements is to be expected, but rather from the minute observations of particular outbreaks of disease by physicians who have studied both the sanitary question and also the nature of the several diseases at present confounded in the term "fever." "

My conclusion was, that the published statistics about Indian fevers (in which statistics, as I think, the sort of fever is not sufficiently distinguished) are without value as evidence either for or against the influence of the earth system upon those diseases; just as (note page 19) I should attach no value to professing evidence on the same subject from English writers who did not take into account whether typhus or enteric fever were in question. I may say that before definitely taking up this position I had the advantage of conferring with Dr. Murchison, whose authority on the subject is admitted by Professor Rolleston. I see no reason to depart from my conclusion, which is indeed, I venture to think, not a jittle confirmed by some of the quotations in Professor Rolleston's paper.

I am, Sir, your obedient servant,

Richmond-terrace, Jan. 24th, 1871 .

George Buchanan.

\section{THE REFORM COMMITTEE AND THE LANCET BILL.}

To the Editor of THE LANCET.

SiR,-On the 18th of January I addressed a letter to you complaining of your having, in your nnmber of the 14th, imputed stratagem to the Reform Committee of the British Medical Association in regard to its proposed mode of dealing with the question of medical reform.

In your last number, that for Jan. 28th, you not only criticise, but misrepresent the contents of my letter, in which Earl De Grey's name was not, as you state, referred to, and in which there was no such absurd statement as that his Lordship, or any Minister, had declared the Association bound to prepare a Medical Act to replace that withdrawn by the Government. The parties who did so were independent members unconnected with the Government.

In criticising a letter which you have not placed before your readers, you have pursued an unprecedented course, which on reflection, I feel assured, you will see the propriety of rectifying.

On behalf of the Association, I am bound to request its publication.

$$
\begin{gathered}
\text { I am, Sir, your obedient servant, } \\
\text { EDWARD WATERs, } \\
\text { Chairman of the Reform Committee of the } \\
\text { Brilish Medical Association. }
\end{gathered}
$$

*** We gladly publish the above letter; but we see no necessity for the publication of Dr. Waters's first one, since we can easily do him full justice without it. We are perfectly willing to believe that there was no "stratagem"-such as we erroneousls suggested-in the conduct of the Reform Committee of the British Medical Association. It now plainly appears that the action of that body resulted simply from its ignorance of the usages of courtesy between public men. It never struck these gentlemen that Tys Larsars Bill ought to be publicly referred to, and its provisions publicly discussed by them, before they attempted to commit the Association to a repudiation of its principles. On a second point we are even more happy to do Dr. Waters justice. We have drawn from him the distinct statement that it is erroneous to suppose the Government gave any sort of hint or encouragement to the British Medical Association to draft a Bill at all. We sincerely beg Dr. Waters's pardon for having so far misunderstood him and the other persons who have written in defence of the action of the Reform Committee. We certainly did for the moment imagine that the Reform Committee were justifying an otherwise unjustifiable action on the ground of a semiofficial position accorded to them by the Government; but it now appears that the Committee only meant to say that "independent members" (not named nor numbered) had advised them to draft a Bill.-Ev. L.

\section{THE MEDICAL PROFESSION IN LINCOLN. To the Editor of The LaveEt.}

Sir,-It would be unfair to the profession in Lincoln to allow the damaging remarks of "Cacouna," in your last week's impression (January 14th) to pass unchallenged.

The statements might have been allowed to stand as true if they had referred to a period six or seven years ago, when one or two bright stars of the profession absorbed the whole of the better class of practice, and left their brethren to fight for dear life in the slums. Lincoln of to-day is a prosperous city, and the medical profession in it is represented by a class of influential and higbly respected gentlemen. Club practice is acknowledged to be an unprofitable and thankless labour, and is usually worked only as a temporary occupation. Clubs frequently go "a beggiug" for a doctor. I have myself met with three instances where deputations have been sent out to request first one medical man and then another to undertalie their contracts, until at last they found some one "short of a job."

Midwifery fees range from one to fire guineas; and in the country, of course, an extra charge is made for the journey. Half-guinea midwifery is not much practised in Lincoln; those who have done so report that they get paid their fee about once in three times, and then only on demand.

The vaccination fee, since the new det came into force, is now five shillings in all cases, excepting of course in those who cannot afford it, who are instructed to go to the public raccinator.

The members of the profession in Lincolu live and work in harmony and goodwill together; they form amongst themselves a Medical Society, which meets twice a year, when papers are read and joviality prevails.

I protest therefore that the statements of your annyymons correspoudent can refer only to exceptional casts, and do not, by any means, characterise the profession in Lincoln.

$$
\begin{aligned}
& \text { I am, Sir, faithfully yours, } \\
& \text { Janum } 17,18 \pi 1 .
\end{aligned}
$$

\section{TEE TORSION OF ARTERIES.}

To the Editor of THi Lancre

SIf,-I have been asked so often as to the form of forcops I recommend for the practice of torsion, and instrmments have been sold as mine which I have no wish to claim, that I send you the clrawings of two pairs of forceps which

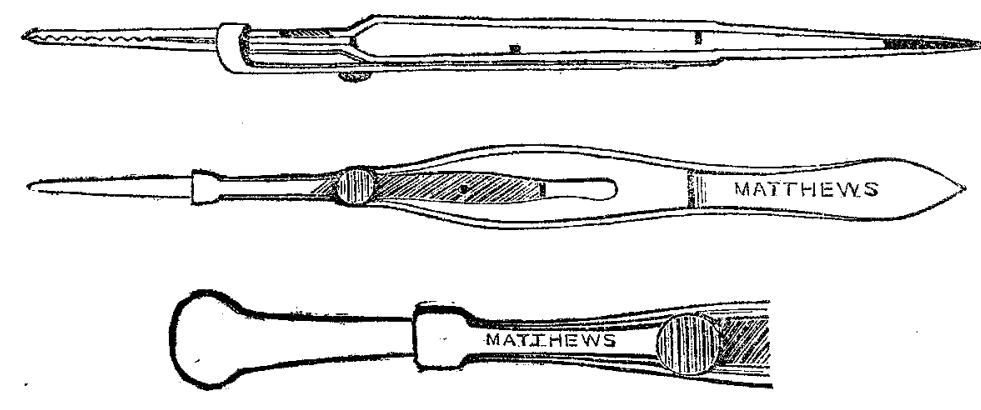

Mr. Matthews, of Portugal-street, made for me some time back. The narrow-bladed pair is for arteries of moderate calibre; the broad pair, for the femoral or brachial arteries. They answer admirably.

Finsbury-square, Jan, 1877
I am, Sir, jours faithfilly,

I'HOFAs Bryants. 